[Deutsche Entomologische Zeitschrift XXVI. 1882. Heft I.]

\title{
Neue Pselaphiden und Scydmaeniden aus Brasilien,
}

\author{
beschrieben von \\ Edm. Reitter in Mödling, bei Wien.
}

(Hierzu Tafel V.)

Von dem um die entomologische Wissenschaft vielfach verdienten Herrn Hans Simon in Stuttgart erhielt ich eine ansehnliche Partie Pselaphiden und Scydmaeniden aus Brasilien zur Determination vorgelegt, die mir Anlafs zu diesem Artikel gaben. Das Material wurde von Herrn Professor Müller um Sao Paolo gesammelt. Ich habe bei dieser Gelegenheit einige Beschreibungen neuer Arten aus Columbien, welche sich in meiner Sammlung vorfanden, den ersteren zugefügt, was den Werth dieser kleinen Arbeit nicht beeinträchtigen dürfte. Für die liberale Mittheilung, theilweise auch Ueberlassung der schönen Thiere, sowie besonders für die Tragung der Kosten für die beigegebene Tafel wird Herrn Simon sowohl von meiner Seite als auch von der Redaction herzlich gedankt.

\section{Pselaphidae.}

\section{Apharus nov. gen.}

Corpus sat latum, convexum, pubescens, antennis crassis, 11-articulatis, basi approximatis, clavatis, palpis quadriarticulatis, articulo ultimo crasso, ovali, introrsum apicem versus excavato, oculis emarginatis. Caput antice subbituberculatum, subtiliter bifoveolatum; prothorax subglobosus, basi trifoveolatus, foveolis minutis; elytra elongata, stria suturali profunde impressa, stria dorsali abbreviata; abdomen segmentis dorsalibus haud marginato-reflexis, segmento primo conspicuo, magnis convexo, segmentis ventralibus quinque perspicuis, primo maximo, reliquis angustis, coxis posticis inter se parum distantibus, tarsi triarticulati, unguiculis binis aequalibus.

Mit Hamotus Aubé verwandt, aber die Fühler dicker, mehr genähert, Halsschild ohne Basal-Querfurche, Hinterleib nicht breit gerandet und aufgeworfen, sondern wiebei Batrisus geformt, erstes Segment lang, die Tarsen mit 2 gleichen Klauen. 
Kopf ähnlich wie bei Tychus. Letztes Glied der Kiefertaster verdickt, oval, innen vor der Spitze ausgehöhlt. Fühler dick, erstes Glied fast doppelt so lang als breit, das nächste ebenso dick, quadratisch, die nächsten 6 quer, allmählig breiter werdend, Glied 9 und 10 gröfser, allmählig breiter werdend, quer, letztes Glied sehr grofs, fast kugelförmig. Augen mälsig grofs, seitlich stehend, gegen die Schläfen ausgerandet, die Ausrandung lang behaart. Halsschild wie bei Bryaxis; alle drei Basalgrübchen punktförmig, ohne Querfurche. Flgd. breit, mindestens so lang als zusammen breit, mit tiefem Naht- und abgekürztem Dorsalstreifen. Das erste sichtbare Dorsalsegment so lang als die folgenden zusammen, alle wie bei Batrisus geformt, und fein, einzeln schräg gerandet, nicht abgesetzt und aufgebogen. Bauch aus 5 Ringen gebildet, der erste sehr lang, die andern kurz. Hinterhüften von einander entfernt. Beine lang und dick, Tarsen 3 gliederig mit zwei gleichen, feinen Klauen. - Von Cercocerus durch die Randung des Abdomens und das Endglied der Taster verschieden.

1. Apharus Mülleri Rttr. n. spec.: Rufo-testaceus, fulvo-pubescens, capite thorace angustiore, fronte bifoveolata, prothorace subgloboso, leviter transverso, foveolis basalibus minutis, elytris ampliatis, thorace sesqui longioribus, parce punctulatis, segmento dorsali primo conspicuo magno distincte punctato. - Long. 2 mill.

Mas: Trochanteribus anticis et femoribus anticis prope basin subtiliter dentatis, metasterno apice impresso.

Patria: Brasilia: Sao Paolo (2600 Fufs über dem Meere). Coll. Hans Simon in Stuttgart. Taf. V. Fig. 4.

Einem Hamotus sehr ähnlich. Fühler sehr dick, den Hinterrand des Halsschildes kaum überragend, das letzte Glied grofs, kugelförmig, wenig länger als breit. Kopf klein, so lang als breit, die Stirnwulst zu zwei nahen Höckern getheilt, kaum sichtbar punktirt, jederseits mit einem kleinen Grübchen. Halsschild etwas breiter als lang und viel breiter als der Kopf, nach vorn etwas mehr als zur Basis verengt, an dieser mit 3 kleinen, punktförmigen Grübchen, wovon die äufseren in den Hinterwinkeln stehen. Flügeldecken fein, das erste sichtbare grofse Rückensegment etwas deutlicher punktirt. Körper gelbroth, etwas glänzend, ziemlich dicht gelb, abstehend behaart.

Bei dem $\sigma^{\top}$ sind die Trochanteren der Vorderbeine und die Vorderschenkel an der Wurzel auf der Unterseite in ein kleines, spitziges Zähnchen erweitert, die Hinterbrust grubenartig eingedrückt and die Mittel- und Hinterschienen vor der Spitze etwas gebogen. 
Es liegen mir $2 \sigma^{\uparrow}$ von H. Prof. Müller gesammelt vor, dem ich diese schöne Art dedicire, welche sich in der Sammlung meines Freundes Hans Simon in Stuttgart befinden.

2. Hamotus gracilicornis Rttr. n. sp.: Obscure castaneus, fulvo-hirtus, palpis tarsisque ferrugineis, vix punctatus, capite parvo, thorace angustiore, oblongo, inter oculos bifoveolato, antennis elongatis, dimidium corporis superantibus, articulis 3-9 quadratis, aut latitudine parum longioribus, clava triarticulata, parum abrupta, articulis duobus penultimis oblongis, aequalibus, ultimo latiore, magno, elongato, obovato, extus sinuato; prothorace oblongo, antrorsum magis angustato, foveolis basalibus subaequalibus, sat magnis; elytris latis, thorace minus longioribus, stria suturali integra discoidalique in medio abbreviata profunde impressis; abdominis segmentis duobus primis dorsalibus conspicuis subaequalibus; tibiis anticis subrectis, posterioribus apice leviter sinuatis. - + Long. fere 3 mill., ơ incognitus.

Patria: Columbia. Coll. Reitter.

Mit den bekannten Arten im Baue des Körpers sehr übereinstimmend, aber durch Grölse und die langen, schlanken Fühler sehr ausgezeichnet. Eine Verbindung zwischen den Basalgrübchen des Halsschildes, wie sie Aubé bei seinem ebenfalls grofsen $\boldsymbol{H}$. lateritius aus Columbien angiebt, ist nicht vorhanden. Das letzte Glied der Fühler ist fast so lang als die 3 vorhergehenden zusammen, gegen die Spitze allmählig dicker, an der Basis leicht geschwungen.

3. Hamotus monachus Rttr. n. sp.: Castaneus, elytris tarsisque ferrugineis, fulvo pubescens, capite thorace vix angustiore, vix oblongo, inter oculos bifoveolato, antennis robustis, articulis 2, 3 quadratis, 4-8 transversis, clava triarticulata magna, bene abrupta, articulis sensim paullulum latioribus, duobus penultimis quadratis, ultimo obovato, magno, duobus praecedentibus longitudine; prothorace subcordato, latitudine haud longiore, laevi, foveolis tribus sulca arcuata connexis impresso; elytris thorace fere sesqui longioribus, parce punctulatis, stria suturali integra discoidalique in medio abbreviata profunde impressis; abdominis segmentis duobus primis. dorsalibus conspicuis subaequalibus; tibiis anticis subrectis, posterioribus leviter sinuatis. - $\{$ Long. 2.2 mill., ot incognitus. - Patria: Yucatan. Coll. Reitter.

Hamotus monachus Saulcy in litt. 
Die Behaarung ist viel feiner als bei Ham. gracilicornis, und darum wohl von $\boldsymbol{H}$. commodus Schauf. auch verschieden, der, wie auch der kleine $\boldsymbol{H}$. humeralis Aubé, eine die Basalgrübchen des Halsschildes verbindende Querrinne besitzt. So lange Herr Dr. Schaufufs uns die Dimensionen der einzelnen Fühlerglieder nicht beschreibt, worauf es bei diesen Thieren hanptsächlich ankommt, so lange werden seine Arten schwer zu deuten sein. Färbung und die sich immer wiederholenden Angaben über die Körperform ohne vergleichende Angaben zu einander, bleiben bei dieser Familie stets Unterschiede letzten Grades.

4. Hamotus clavicornis Rttr. n. sp.: Rufo-castaneus, fulvopubescens, palpis tarsisque testaceis; capite thorace vix angustiore; inter oculos bifoveolato; antennis brevibus, crassis, articulo secundo quadrato, $3-8$ transversis, sensim magis transversis, clava sat bene abrupta, triarticulata, articulis sensim parum latioribus, duobus penultimis valde transversis, ultimo maximo, latiore, ovato, apice obtuse rotundato, fere tribus praecedentibus longitudine; thorace subcordato, latitudine haud longiore, laevi, foveolis basalibus tribus sat magnis, subaequalibus, elytris thorace plus sesqui longioribus, parcissime vix perspicue punctulatis, stria suturali integra dorsalique ante medium abbreviata profunde impressis; abdominis segmentis duobus primis dorsalibus conspicuis subaequalibus; tibiis anticis subrectis, posterioribus sinuatis. - $q$ Long. 2.2 mill., $\delta$ latet.

Patria: Venezuela. Coll. Reitter.

Durch die kurzen Fühler mit queren Mittelgliedern recht bemerkenswerth.

5. Hamotus tritomus Rttr. n. sp.: Rufo-ferrugineus, fulvopubescens, palpis pedibusque rufo-testaceis, vix punctatis, capite thorace vix angustiore, inter oculos bifoveolato, antennarum articulo primo cylindrico, secundo quadrato, $3-8$ parum minoribus, transversis, clava triarticulata valde abrupta, sensim paulo latiora, articulis duobus penultimis subquadratis, ultimo magno, ovato, praecedente sesqui longiore, prothorace subcordato, foveolis lateralibus cum sulca transversa connexis, foveola media vix perspicua; elytris thorace sesqui longioribus, stria suturali integra dorsalique abbreviata fortiter impressa, abdominis segmentis duobus primis conspicuis dorsalibus 
subaequalibus, tibiis posterioribus minus sinuatis. - Long. 2 mill. - Patria: Columbia: Sito; Ambalema. Coll. Reitter ').

Ich besitze 2 Weibchen von dieser schönen Art, welche sich durch die grofse 3gliederige Fühlerkeule, die viel mehr als $\frac{1}{3}$ der gesammten Fühlerlänge einnimmt, und durch die tiefe Basalfurche des Halsschildes auszeichnet, in deren Grunde das Mittelgrübchen kaum zu entdecken ist.

\section{Batrisus Aubé.}

Diese sehr artenreiche Gattung läfst sich in nachfolgende Subgenera zerlegen, auf die der Kürze und leichteren Uebersicht wegen bei ferneren Neubeschreibungen Rücksicht genommen werden sollte. Ihre Deutung wird sodann wesentlich erleichtert sein.

Bei allen Arten hat nur das erste sichtbare Rückensegment eine scharfe Seitenrandkante.

1) Mir ist noch nachfolgende unbeschriebene Art bekannt:

Hamotus singularis Rttr. n. spec.: Rufo-castaneus, palpis tarsisque rufis, fulvo-pubescens, vix punctatus, capite thorace fere aequilato, inter oculos bifoveolato, antennis mediocribus, articulo primo latitudine duplo longiore, articulis 2-3 quadratis, ceteris sensim magis subtransversis, clava vixabrupta, articulis penultimis transversis praecedentibus parum latioribus, ultimo crasso, maximo, subglobosim obovato, praecedente duplo latiore; prothorace subcordato, latitudine haud longiore, basi trifoveolato, elytris thorace parum longioribus, stria suturali integra dorsalique valde abbreviata profunde impressa, abdominis segmento dorsali primo conspicuo secundo parum longiore, tibiis anticis rectis, posterioribus leviter sinuatis.

Mas: tibiis posticis apice longe calcaratis, calcaribus sensim apice subincrassatis.

Patria: Mexico. Gefunden von Bilimek. In meiner Samml.

Von $\boldsymbol{H}$. suturalis Schauf. und commodus Schauf. sicher durch die nicht durch eine Querfurche verbundenen Grübchen des Halsschildes verschieden. An den Fühlern sind die 2 queren, ziemlich kleinen vorletzten Glieder wenig abgesetzt, dagegen das letzte rundlich eiförmige Glied aufserordentlich stark verbreitert. Die Hinterschienen des $\sigma^{\tau}$ haben einen langen Sporn, der gegen die Spitze sichtlich dicker wird. 
Die scharfe Seitenrandlinie des ersten Rückensegments erreicht nicht die Mitte desselben; dieses von hier zur Spitze stielrund; das schräge Sublateralfältchen ist nur am ersten und vierten Segmente vorhanden, das 3te und 4te vollständig ungerandet. Endglied der Taster kurz, verkehrt spindelförmig, an der Wurzel dünn, über der Mitte verdickt. Halsschild mit 3 Längsfurchen, ohne Basaldörnchen. Fld. mit abgekürztem Dorsalstreifen. Aubé: Batrisus ${ }^{1}$ ).

Die scharfe Seitenrandkante des ersten Segments erreicht fast die Spitze desselben; Endglied der Taster länglich, spindelförmig, an der Wurzel breiter, gegen das Ende zugespitzt.

Alle 4 Rückensegmente mit feinen Sublateralkielchen. Halsschild mit 3 Längsfurchen und mit deutlichen Basaldörnchen. Fld. mit kurzem Dorsalstreifen.

Rttr.: Batrisodes.

Nur das 1ste und 4te Segment mit feinen Sublateralkielchen, das 2 te und 3 te höchst fein linienförmig gerandet. Halsschild ohne Dörnchen. Fld, ohne Dorsalstreifen.

Halsschild mit Seitenfurchen, Mittelfurche fehlt.

Halsschild ohne Längsfurchen.

Reitter: Syrbatus. Leconte: Arthmius.

6. Batrisus (Syrbatus) clypeatus Rttr. n. sp.: Rufus, nitidus, pubescens, capite thoracis latitudine, fronte antrorsum profunde exciso, margine antice deflexo valde foveolatoque, lateribus elevato, vertice subtilissime longitudinaliter cristato, clypeus productus, apice subrotundato, postice tuberculato, antennarum articulo primo inflato, apice magis incrassato, introrsum apice rotundatim producto, supra canaliculato, ceteris angustioribus, articulis $3-8$ subaequalibus, leviter oblongis, ultimis tribus magis incrassatis, duobus penultimus subglobosis, ultimo obovato, apice acuminato; prothorace subcordato, haud transverso, ante basin sulca tenui transversa impressa, utrinque foveolata, sulca laterali longitudinaliter insculpta, media nulla, elytris globoso ampliatis, laevibus, stria suturali distincta, discoidali nulla, abdominis segmento primo dorsali majore, foveolis lateralibus parum perspicuis, in medio haud foveolato, tibiis posticis breviter calcaratis. - Long. 2 mill. Taf. V. Fig. 6.

Mas: tibiis intermediis apice calcaratis.

1) Diese Gruppe dürfte wegen dem abweichenden Endgliede der Taster, sowie den völlig ungerandeten mittleren Abdominalsegmenten vielleicht eine selbstständige Gattung bilden. 
Patria: Brasilia: Sao Paolo (3000 Fufs über dem Meere). Coll. Hans Simon.

Durch die Kopfbildung erinnert diese Art an unseren Batrisus oculatus; das Halsschild hat aber weder eine Mittellängslinie noch Basaldörnchen.

Mir liegen 2 wohlerhaltene Männchen vor.

7. Batrisus (Syrbatus) Phantasma Rttr. n. spec.: Testaceus pubescens, capite magno, thorace latiore, antice profunde excavato, lateribus cavam, utrinque in lobam duobus dentiformibus productis, dente posteriore extus dense piloso, clypeus apice triangulari, fronte punctata, foveola oculari oblonga, antennis elongatis, articulo primo incrassato, suboculto, ceteris suboblongis, clava minus abrupta, articulis duobus penultimis suboblongis, fere globosis, ultimo elongato, apice acuminato; prothorace subcordato, longitudine fere breviore, vix perspicue punctato, sulca transversa ante basin, longitudinali prope lateribus sat fortiter impressis, elytris globoso ampliatis, vix punctulatis, stria suturali distincta, dorsali nulla, abdominis segmento primo dorsali majore, pliculis brevissimis; tibiis posticis tenuiter calcaratis. - Long. 1.5 mill. Taf. V. Fig. 7.

Mas: trochanteribus intermediis spinosis, femoribus anticis et tibiis anticis intus in medio subdentatis, tibiis intermediis calcaratis.

Patria: Brasilia: Sao Paolo (4000 Fufs über dem Meere). Coll. Hans Simon.

Von B. clypeatus durch grölseren, längeren, anders gebildeten Kopf und die Geschlechtsdifferenzen sehr verschieden.

Ein einzelnes, etwas beschädigtes Männchen.

8. Batrisus (Syrbatus) sublyratus Rttr. n. spec.: Rufus, pubescens, palpis tarsisque testaceis, capite thoracis latitudine, fronte inter antennas transversim impressa, impressione in medio interrupta, prope oculos foveolato, vertice breviter carinato, antrorsum obsolete longitudinaliter subimpresso, lateribus leviter obtuse elevato, thorace subcordato, lateribus antice subangulato, ante basin sulca transversa impressa, ante angulos posticos foveolato et sulca longitudinali sublaterali impressa, intermedia nulla, elytris globoso ampliatis, stria suturali distincta, dorsali nulla, abdominis segmento primo dorsali majore, pliculis basalibus brevissimis plus quam tertiam disci partem includentibus, tibiis posticis apice spinula, tenui subarcuata armatis. - Long. 2.2 mill.

Mas: incognitus. 
Patria: Brasilia: Sao Paolo (3000 Fufs über dem Meere). Coll. Hans Simon.

Es liegen mir von dieser Art 2 Weibchen vor. Diese Art ist der nächsten sehr ähnlich, unterscheidet sich jedoch durch die Sculptur des Kopfes. Die Fühler sind schlank, das 2te bis 7 te Glied länger als breit, das 5te merklich länger als die umgebenden, das 8te klein, rund, 9 und 10 breiter, kugelig, das letzte lang eiförmig, zugespitzt, etwas breiter als die vorhergehenden.

9. Batrisus (Syrbatus) simplicifrons Rttr. n. sp.: Rufus, pubescens, palpis tarsisque testaceis, capite prothoracis latitudine, fronte subquadrato, antrorsum profunde impresso, impressione in medio interrupta, prope oculos foveolato, lateribus leviter obtuse elevato, antennarum articulis $3-7$ leviter oblongis, 8 parum minore, clava vix abrupta, articulo 9 suboblongo, 10 fere quadrato, ultimo minus latiore, oblongo, apice acuminato, prothorace subcordato, latitudine parum longiore, sulca transversa ante basin, sulcoque longitudinali sublaterali impressis, foveola ante angulos posticos parva; elytris globoso ampliatis, vix punctulatis, striola suturali impressa, dorsali nulla, abdominis segmento primo dorsali majore, pliculis basalis brevis fortiter elevatis, vix dimidiam disci partem includentibus; tibiis posticis breviter calcaratis. - Long. 2.2 mill.

$\mathrm{M}$ as: fronte margine antice in medio subangulato, impressione transversa antice in medio vix interrupta, antennarum articulo primo magis inflato, tibiis intermediis robustioribus, apice fortiter calcaratis.

Patria: Brasilia: Sao Paolo (3000 Fufs über dem Meere). Coll. Simon, Reitter.

Bei den $\jmath^{\uparrow}$ ist der Vorderrand der Stirn zwischen den Fühlern eckig erweitert, die Querfurche vor demselben in der Mitte nicht unterbrochen, das Wurzelglied der Fühler dicker, die Mittelschienen robuster mit einem starken Endsporne.

10. Ratrisus (Syrbatus) calc̀arifer Rttr. n. sp.: Rufo-testaceus, pubescens, palpis tarsisque pallidis, capite cum oculis thorace fere latiore, fronte transversim quadrata, antrorsum sulca transversa in medio interrupta impressa, prope oculos foveolato, utrinque punctulato, vertice obsolete longitudinaliter foveolato, antennarum articulis 4-10 subglobosis, duobus penultimis parum majoribus, ultimo obovato, apice acuminato, prothorace subcordato, latitudine fere longiore, sulca transversa tenui ante basin, longitudinali prope 
lateribus impressis, foveola ante angulos posticos parva, elytris globoso ampliatis, laevibus, striola suturali distincta, discoidali nulla, abdominis segmento primo dorsali majore, pliculis brevissimus, convergentibus, latitudine dimidiam segmenti partem includentibus; tibiis posticis sat longe calcaratis. - Long. 1.8 mill.

Mas: latet.

Patria: Brasilia: Sao Paolo (3000 Fufs über dem Meere). Coll. Hans Simon.

Auf dem Scheitel befindet sich, anstatt des gewöhnlichen Leistchens, ein längliches Grübchen; die Seiten des Kopfes sind schwach aufgeworfen, punktirt.

Nur ein einzelnes Weibchen.

11. Batrisus (Syrbatus) brevispinus Rttr. n. sp.: Rufus, pubescens, palpis tarsisque testaceis, capite cum oculis thorace latiore, fronte transversim quadrata, punctata, antice fovea transversa magna impressa, foveola laterali angusta, antennarum articulis $3-7$ suboblongis, 8 parvo, rotundato, 9, 10 parum majoribus, globosis $11^{\circ}$ magno, obovato, apice acuminato, prothorace subcordato, latitudine vix longiore, sulca transversa tenui ante basin, longitudinali prope lateribus impressis, elytris globoso ampliatis, stria suturali distincta, discoidali nulla; tibiis posterioribus parum, anticis tenuis introrsum magis curvatis, posticis apice brevissime calcaratis.

Mas: latet. - Taf. V. Fig. 8.

Patria: Brasilia: Sao Paolo (3000 Fufs über dem Meere). Coll. Hans Simon.

Dem Vorigen sehr ähnlich, die Hinterschienẹn haben aber nur einen sehr kurzen Enddorn, die Vorderschienen sind dünn und nach innen stark gebogen, die Stirn hat am Vordertheile eine tiefe, grofse, quere Grube, in welche die kleinen Seitengrübchen einmünden.

Nur ein einzelnes defectes Weibchen.

12. Batrisus (Arthmius) tripunctatus Rttr. n. sp.: Rufus, palpis pedibusque testaceis, pubescens, capite magno, thorace parum latiore, subtilissime parce punctulato, vertice trifoveolato, foveola intermedia minore, lateribis minus elevato, margine antice deflexo, tuberculo antennari gibboso, opaco, antennarum articulis $3,4,6,8$ subquadratis, 5,7 subelongatis, clava triarticulata parum abrupta, articul. duobus penultimis subglobosis; prothorace subcordato, haud transverso, sulca transversa ante basali 
et utrinque foveola impressis; elytris globoso ampliatis, vix punctatis, stria suturali distincta, dorsali nulla, abdomine segmento primo dorsali majore, pliculis segmentam latitudine plus quam dimidiam disci partem includentibus; tibiis anticis rectis, postice brevissime calcaratis. - Long. 1.6 mill.

Mas: Callo humerali prominulo, trochanteribus anterioribus breviter angulatis, tibiis intermediis intus ante apicem parum emarginatis, apice brevissime calcaratis.

Patria: Columbia: Bogota. Coll. Reitter.

Diese Art ist durch die 3 Scheitelgrübchen und die matten, stark beulenförmig vortretenden Fühlerhöcker sehr leicht kenntlich. An der Basis des Halsschildes befinden sich aufser dem normalen Grübchen, in welche die Querfurche einmündet, 2 kleine punktförmige Grübchen in der Nähe der Hinterecken, die zwar den anderen Arten auch zukommen, bei dieser aber sehr deutlich sichtbar sind.

Es liegen mir $2 \delta^{t}$ und 1 오 vor.

13. Batrisus (Arthmius) Luzerae Rttr. n. sp.: Castaneus, capite obscuriore, elytris pedibusque rubris, palpis tarsisque testaceis, pubescens, capite magno, thorace fere parum latiore, subrugoso, tuberculis antennariis valde gibbosis, foveola oculari antrorsum in sulcis productis, sulcis antice conjunctis, vertice foveolato; antennarum articulis 3, 4, 6, 8 subquadratis, 5, 7 oblongis, clava triarticulata, parum abrupta, articulis duobus penultimis quadratosubtransvis; prothorace subcordato, vix transverso, sulca transversa ante basali et utrinque foveola impressis; elytris ampliatis, vix punctatis, stria suturali distincta, discoidali brevissime obsoleta, callo humerali subangulato, abdomine segmento dorsali primo majore, pliculis brevissimis, subobsoletis, segm. latitudine plus quam dimidiam disci partem includentibus, tibiis leviter curvatis. Long. 1.8 mill.

Patria: Columbia: La Luzera. Coll. Reitter.

Dem B. tripunctatus ähnlich, der Kopf.ist aber runzelig sculptirt, die Fühlerhöcker grölser, dazwischen mit einem Eindrucke, in welchem auch die seitlichen Stirnfurchen einmünden, das Scheitelgrübchen ist grölser, alle Schienen leicht gebogen, die Fld. weniger kugelig, mit schwach zahnförmig vortretender Schulterbeule, dicht daneben mit einem schwachen Längseindruck. Ich besitze von dieser Art nur ein einzelnes Weibchen. 
14. Batrisus (Arthmius) bicolor Rttr. n. sp.: Rufus, palpis testaceis, capite prothoraceque nigris, pubescens, fronte transversim quadrato, antrorsum transversim impresso, impressione in medio interrupta, vertice intermediis subglobosis, ultimis tribus parum majoribus, duobus penultimis globosis, articulo ultimo praecedentibus latiore, obovato, prothorace capite vix angustiore, subcordato, latitudine vix longiore, ante basin utrinque foveola oblonga, sulca tenui transversa impressis, sulcis longitudinalibus nullis, elytris globoso ampliatis, vix perspicue parce punctulatis, stria suturali distincta, discoidali nulla; abdominis segmento primo dorsali majore, pliculis basalibus brevissimis, extis subfoveolato, in medio vix impresso; tibiis posticis tenuiter calcaratis. - Long. fere 1.5 mill.

Mas: incognitus.

Patria: Brasilia: Sao Paolo (400 Fufs über dem Meere). Coll. Hans Simon.

In der Färbung dem B. rhinoceros Schauf. ähnlich, aber kleiner, Scheitel ohne Längskiel.

Zum Verständnisse nachfolgend beschriebener Arten mag an dieser Stelle gegeben werden eine

Uebersicht der mit Bryaxis verwandten Gattungen.

Die 3 ersten sichtbaren Rückensegmente gerandet und fast immer aufgebogen; Endglied der Taster kurz spindelförmig oder oval.

Fühler in beiden Geschlechtern 10gliederig; erstes Rückensegment grofs, plattenförmig verlängert mit langen Dorsalstrichen. Halsschild mit 3 Grübchen. Fld. mit Dorsalstreifen. Korper lang behaart. . . . Brendel: Decarthron ${ }^{1}$ ). Fühler 11gliederig.

Fld. mit Dorsalstreifen; erstes sichtbares Rückensegment deutlich länger als die folgenden.

Der umgeschlagene Rand der Flügeld. ohne Sublateralfurche.

Die 3 Basalgrübchen des Halssch. stehen frei. Abmen ohne Grube.

Erstes Fühlerglied einfach, wenig länger als breit.

Leach.: Bryaxis.

1) Von Bryaxis durch gedrungene Gestalt, lange Behaarung und 10gliederige Fühler abweichend. 
Erster Fühlerglied stark verlängert, die innere Apicalecke zahnartig vortretend, das folgende an der Aufsenecke des ersten angefügt.

Schaufufs: Gonathocerus ${ }^{1}$ ).

Halsschild mit Basalquerfurche, das mittlere Grübchen fehlt; Abdomen zwischen den Dorsalstricheln mit einem Basalgrübchen. . . . . Rttr.: Acamaldes ${ }^{2}$ ).

Der umgeschlagene Rand der Fld. mit Sublateralfurche. Die drei Grübchen des Halsschildes durch eine quere Furche verbunden. Spitzenrand der Fld. in der Mitte beim $\sigma^{\star}$ mit einem lappenförmigen, häufig häutigen Anhang. . . . . . . . . . Saulcy: Rybaxis ${ }^{3}$ ). Flügeldecken ohne Dorsalstreifen.

Fld. mit Nahtstreifen.

Erstes sichtbares Rückensegment wenig länger als eines der folgenden. Körper mehr oder minder behaart.

Fld. an der Basis mit 4 kleinen Grübchen. Fühler in beiden Geschlechtern deutlich 11 gliederig. Halssch. jederseits an der Basis mit einem Grübchen. Die fein gerandeten Seiten des Abdomens nicht aufgebogen. . . . . . . . . . . Rttr.: Xybaris ${ }^{4}$ ).

Fld. an der Basis ohne Grübchen. Letztes Glied der Fühler beim $\sigma^{\top}$ mit dem 10ten verwachsen. Hals-

1) Nunquam otiosus p. 506. - Der Autor will diese Gattung wegen der Fühlerbildung zu Rhexius stellen, was aber nicht statthaft ist, da sich dieselbe von Bryaxis nur durch dieselbe unterscheidet.

2) Ich habe diese Gattung als Subgenus, bei Beschreibung der Bryaxis bythinoides von der Goldküste, an gleichem Orte beschrieben; reclamire jedoch nun dafür die Gattungsberechtigung.

3) $\mathrm{Zu}$ den vielen Unterschieden, die wir bereits von Rybaxis kennen, konnte ich noch jetzt den noch nicht bekannten sexuellen zufügen; ich habe an allen mir bekannten exotischen Arten dieser wohlbegründeten Gattung die Flügeldeckenbildung angetroffen.

4) Entfernt sich von Bryaxis, dem diese Gattung, namentlich den Arten des Subgenus Reichenbachia aufserordentlich ähnlich sieht, durch sehr schmal gerandetes, nicht aufgebogenes Abdomen. Halsschild nur jederseits mit einem Grübchen. 
schild ohne Grübchen. Die gerandeten Seiten des Abdomens aufgebogen. . . . . King: Eupines ${ }^{1}$ ).

Erstes sichtbares Rückensegment stark verlängert. Abdomen sehr schmal gerandet.

Körper sehr fein behaart. Basis der Fld. ohne Grübchen. . . . . . Leconte: Scalenarthrus ${ }^{2}$ ).

Körper kahl. Flügdel. an der Basis mit einem Grübchen im Nahtstreifen und einer Grube neben den Schultern. Glied 9 und 10 der Fühler stark quer, 11 sehr grofs, lang eiförmig.

Leconte: Eupsenius ${ }^{3}$ ).

Flügeld. ohne Naht und Dorsalstreifen, Halsschild ohne Grübchen, mit einer schwachen Basalquerfurche. Seiten des Abdomens fein gerandet, das erste Segment länger. . . . . . . . . Leconte: Pselaptus ${ }^{4}$ ).

Nur das erste sichtbare längere Rückensegment gerandet. Endglied der Palpen zugespitzt, schwach beilförmig. Fühler 11 gliederig. Halsschild mit tiefer Basalquerfurche, jederseits mit einem Grübchen; das Mittelgrübchen fehlt. Fld. ohne Dorsalstreifen. . . . . . Rttr.: Batrybraxis ${ }^{5}$ ).

Hinterleib vollkommen ungerandet. Endglied der Palpen oval, schwach beilförmig. Fühler 11 gliederig, das 9 te u. 11 te Glied verdickt. Halsschild ohne Grübchen und Furchen, am Seitenrande mit einem kleinen Höckerchen. Fld. ohne Naht und Rückenstreifen. Basis des ersten Rückensegments mit mehreren kleinen Grübchen. Westw. Sathytes ${ }^{6}$ ).

1) Mit dieser Gattung ist identisch: Byraxis Rttr., Verh. d. Nat. Ver. in Brünn 1880 , p. 166.

$\left.{ }^{2}\right)$ Trans. A m. Ent. Soc. 1880, 185.

3) Mit Bryaxis ebenfalls sehr nahe verwandt, einen Uebergang zu Trimium gewissermafsend darstellend.

4) Trans. Am. Ent. Soc. 1880, 184.

$\left.{ }^{5}\right)$ Bildet einen Uebergang zu Batrisus. Die Taster sind mehr jenen von Bythinus ähnlich, nur ist das Endglied viel kleiner. Das Abdomen ist nur am ersten Segmente gerandet.

$\left.{ }^{6}\right)$ Trans. Ent. Soc. Lond. 1870, II. 128. Mir ist diese Gattung unbekannt. 
15. Decarthron bipunctatum Rttr. n. sp.: Rufum, nitidum, convexum, palpis tarsisque testaceis, longe pubescens, capite thorace vix angustiore, utrinque foveola parva impressa, oculis grandibus, rotundatis, prothorace transverso, subcordato, laevi, foveolis lateralibus nullis, foveola antescutellari minuta, profunde impressa; elytris latis, stria suturali et discoidali apice abbreviata profunde insculpta parce subtilissime punctulatis, striolis abdominalibus levissime divergentibus, fere parallelis, longitudine dimidiam segmenti partem superantibus, plus quam dimidiam disci partem includentibus; antennis sat tenuibus, articulis $3-8$ quadratis, articulo 9 paullulum majore, clava subbiarticulata; tibiis subrectis, posticis leviter sinuatis. Long. 1.3 mill.

Patria: Columbia. Coll. Reitter.

Dem Decarthron stigmosum ähnlich, aber etwas kleiner, lebhafter roth, mit dünneren Fühlern. Auf dem Kopfe sind nur zwei deutliche Grübchen vorhanden; vor denselben ist manchmal unter jedem einzelnen noch die Spur eines anderen angedeutet.

Ich besitze 3 ㅇ aus Carracas.

16. Bryaxis nasuta Rttr. n. sp.: Rufo-testacea, palpis pedibusque pallidis, brevissime vix perspicue pubescens, capite thorace haud angustiore, fronte magna, plana, juxta oculos grandiores foveolata, margine antice in medio subdeflexo et foveolato, antennis elongatis, articulis 1-6 oblongis, tertio longiore, 7 et 8 quadratis, clava triarticulata, minus abrupta, his articulis sensim latioribus, duobus penultimis oblongo-quadratis, ultimo magno, ovato; palporum articulo ultimo elongato, prothorace subcordato, vix transverso, foveolis lateralibus parvis, intermedia minutissima; elytris vix punctatis, stria dorsali ante apicem abbreviata, striolis abdominalibus brevissimis, longitudine sextam partem aequantibus, tertiam disci partem includentibus; pedibus gracilibus, longioribus, tibiis basi tenuibus, subrectis, posticis leviter sinuatis. - Long. 1.5 mill.

Mas: antennarum articulo quinto sextoque incrassato, quinto subquadrato, sexto elongato; tibiis intermediis intus paulo ante apicem spinula armatis.

Patria: Honda am Magdalena. Coll. Reitter.

Diese Art ist durch blasse Färbung, lange Fühler und Beine recht ausgezeichnet; sie gehört in die Untergattung Reichenbachia und in die Verwandtschaft der Br. eucera Aubé. Die Stirn ist ziemlich eben, grofs, viereckig, neben den Augen befindet sich das 
gewöhnliche Grübchen; das vordere ist im Vorderrande der Stirn eingefügt, und gleichzeitig ist diese Stelle etwas nach abwärts geneigt, wodurch der Stirnrand fast in zwei kurze, stumpfe Zipfeln ausgezogen erscheint.

17. Bryaxis biclavata Rttr. n. sp.: Nigro-brunnea, elytris rubris, tibiis tarsisque ferrugineis, palpis testaceis, brevissime vix perspicue pubescens, capite thorace haud angustiore, fronte bifoveolata, foveola antice valde obsoleta, oculis mediocribus, prothorace vix transverso, foveolis lateralibus sat parvis, ante scutellari minutissima, punctiformi; elytris stria dorsali subtiliter insculpta striolis abdominalibus brevissimis, plus quam tertio segmentam partem includentibus, tibiis subrectis, posticis leviter sinuatis. - Long. 1.8 mill. Taf. V. Fig. 10.

Mas: antennis articulis 3 et 4 parvis, transversis, 5 et 6 valde magnis, incrassatis, irregularibus, quinto majore introrsum excavato et bispinuloso, sexto fere subquadrato, articulis 7, 8 subquadratis, clava triarticulata, parum abrupta, his articulis sensim minus latioribus, duobus penultimis quadrato-oblongis; trochanteribus tibiisque simplicibus.

Patria: Bogotà. Coll. Reitter.

Eine neue Reichenbachia, die wegen der Bildung der männlichen Fühler ebenfalls mit Br. eucera Aubé in nahe Verwandtschaft tritt, und unserer impressa ähnelt, nur ist sie gröfser, die vordere Grube des Kopfes ist verflacht und fast ganz erloschen und Trochanteren und Schienen des $\delta$ sind einfach.

Mir liegt nur ein einzelnes, schön erhaltenes $\delta$ vor.

18. Xybaris spiniceps Rttr. n. spec.: Parva, rufo-testacea, brevissime, vix perspicue pubescens, capite magno, thorace haud angustiore, in mare profunde excavato, temporibus extus dentato-productis, in medio antice tuberculato, antennis elongatis, articulis subquadratis, clava triarticulata, obscuriore, articulo ultimo elongato ovato, prothorace subcordato, longitudine parum latiore, foveolis lateralibus distinctis, puncto antescutellari vix perspicuo, elytris convexis, vix perspicue punctulatis, stria suturali integra, dorsali nulla, basi foveolis punctiformibus quatuor impressis, striolis abdominalibus brevissimis, tertiam segmenti partem includentibus; tibiis anticis pone medio intus emarginatis, tenuibus, apice curvatis, intermedius ante apicem obluse dentatis, posticis in medio sinuatis. - Long. $\sigma^{\top}$ 1.0 mill., 오 incognita. Taf. V. Fig. 11. 
Patria: Brasilia: Sao Paola (2600 Fufs über dem Meere). Coll. Hans Simon.

Gelbroth, glänzend, stark gewölbt, gedrungen, schwer sichtbar, fast staubartig behaart. Fühler lang, den halben Körper überragend, die Keule grofs, dreigliederig, wenig abgesetzt, allmählig breiter werdend, die vorletzten Glieder so lang als breit, das letzte lang eiförmig. Kopf des $\sigma^{\tau}$ grofs, fast breiter als das Halsschild, oben tief ausgehöhlt, die Schläfen hinter den Augen nach auf- und auswärts lang flügelförmig erweitert, am vorderen Theile der Grube in der Mitte mit einem Höckerchen. Halsschild etwas breiter als lang, von gewöhnlicher Bryaxis-Form, gewölbt, die Seitengrübchen deutlich, das mittlere Basalgrübchen kaum angedeutet. Fld. viel breiter, kugelig gewölbt, so lang als zusammen breit, oben kaum punktirt, mit ganzem Nahtstreifen, an der Basis jede mit 4 punktförmigen kleinen Grübchen, wovon das innerste in der Wurzel des Nabtstreifens steht. Abdomen kurz, gewölbt, verschmälert, schmal gerandet, die Ränder nicht aufgebogen, die Dorsalstrichelchen des ersten sichtbaren Segments sehr kurz, ein Drittel der Segmentsbreite einschliefsend. Die Vorderschienen des $\sigma^{x}$ sind gegen die Spitze verdünnt, unter der Mitte gekrümmt, die mittleren unter der Mitte innen stumpf gezähnt und die hinteren unter der Mitte nach innen gebogen.

Das $q$ ist unbekannt; mir liegt nur ein einzelnes $\sigma^{\top}$ vor.

19. Xybaris troglocera Rttr. n. sp.: Parva, rufo-castanea, nitida, brevissime vix perspicue pubescens, fere glabra, capite magno, antice transversim impresso, impressione subbifoveolata, prope oculos magnos foveolato, antennis sat brevibus, articulis $3-8$ leviter, 9 fortiter transversis, clava biarticulata, articulo penultimo triangulare, ultimo magno ovato, intus excavato; prothorace subcordato, leviter transverso, foveolis lateralibus obsoletis, antescutellari fere nulla, elytris convexis, vix punctulatis, stria suturali integra, dorsali nulla, basi foveolis punctiformibus quatuor impressis, striolis abdominalibus quartam segmenti longitudinem aequantibus, quintam disci partem includentibus, tibiis posticis leviler sinuatis. $-\delta$ Long. 1 mill., 우 incognita.

Patria: Columbia, Ubaque. Coll. Reitter $1 \sigma^{\top}$.

Der vorigen Art sehr ähnlich, der Kopf ist jedoch von der Breite des Halsschildes, oben eben, am Vorderrand mit einer geraden, feinen Querfurche; in dieser mit zwei undeutlichen Grübchen; aufserdem mit zwei Grübchen zwischen den Augen. Mit 
Bryaxis denticornis Schauf., die jedenfalls trotz der kaum richtigen Angabe der zehngliedrigen Fühler, hierher gehört, verwandt, aber durch andere Sculptur des Kopfes verschieden.

20. Batrybraxis fortis n. spec.: Brunneo-castanea, nitidissima, fulvo-pilosa, vix punctata, capite antice semicirculariter impresso, utrinque foveolato, antennis obscure rufis, prothorace capite vix latiore, transverso, subcordato, ante basin profunde transversim sulcato, elytris latis, ante apicem latissimis, vix perspicue punctatis, thorace fere duplo longioribus, basi in medio foveola punctiformi levius impressa, abdominis segmento primo majore parce subtilissime punctulato, striolis haud conspicuis, ceteris angustis, sensim subacuminatis, palpis pedibusque rufo-testaceis. - Long. 1.6 mill. Taf. V. Fig. 5 .

Fem.: antennarum articulis duobus primis leviter incrassatis, primo latitudine plus quam sesqui longioribus, secundo quadrato, $3-8$ transversis, ultimis tribus majoribus, sensim latioribus, $9^{\circ}$ fortiter, $10^{\circ}$ leviter transverso, elongato-ovato, tibiis intermediis parum, posticis intus ante apicem fortiter curvatis.

Mas: antennarum articulis $6-7$ maxime transversis, angustis, $8^{\circ}$ et $9^{\circ}$ valde inflatis, irregularibus; tibiis magis curvatis, ceteris ut in feminae.

Patria: Brasilia: Sao Paolo (3000 Fufs über dem Meere). Coll. Hans Simon.

Vom Aussehen eines Batrisus, die Fülse jedoch nur mit einer Klaue. Dunkel kastanienbraun, sehr glänzend, lang, gelblich behaart, kaum punktirt, Fühler wenig heller, Taster und Beine gelbroth. Kopf von der Breite des Halsschildes, Stirn viereckig mit aufgebogenem Vorder- und Seitenrande, jederseits mit einem Grübchen. Augen rund, mäfsig vorragend. Schläfen hinter den Augen verrundet. Fühler von halber Körperlänge, lang bebaart, die beiden Wurzelglieder dicker als die folgenden, das erste mehr als anderthalb Mal so lang als breit, das 2te quadratisch, die folgenden quer, die Keule 3gliederig, allmählig breiter werdend, Glied 9 stark, 10 schwach quer, das letzte lang eiförmig; beim $\sigma^{\tau}$ ist das 4 te bis 7 te Glied äufserst quer, linsenförmig, das 7 te fast verschwindend, Glied 8 und 9 sebr verbreitert und vergrölsert, unregelmälsig, das $\cdot 8$ te gröfser. Halsschild leicht quer, schwach herzförmig, vor der Basis mit einer geraden, tiefen Querfurche. Fld. etwas länger als zusammen breit, unter der Mitte am breitesten, gewölbt, mit ganzem Nahtstreifen, der Dorsalstreifen 
fehlt, an der Basis in der Mitte mit einem flachen Punktgrübchen. Abdomen gegen die Spitze zugespitzt, erstes sichtbares Segment länger als die folgenden, allein an den Seiten gerandet, oben wenig sichtbar, zerstreut punktirt. Beine schlank, die 4 hinteren Schienen beim $q$ deutlich, beim $\sigma^{\nearrow}$ gegen die Spitze stärker gebogen und verbreitert.

Es liegen mir von dieser schönen Art $2 \sigma^{\pi}$ und ein gebrochenes 우 vor.

21. Batrybraxis curtula nov. spec.: Rufa, nitida, fulvopubescens, capite transverso, antice transversim impresso, utrinque foveolato, antennis gracilibus, antennarum articulis 3-9 leviter transversis, clava biarticulata, articulo 10 subquadrato, prothorace transverso, ante basin constricto, profunde transversim sulcato, elytris valde convexis, thorace fere duplo longioribus, parce minus perspicue punctulatis, basi in medio puncto majore levius impressis, abdominis striolis dorsalibus distinctis, brevibus, approximatis, septimam segmentam disci partem includente; tibiis apicem versus levissime dilatatis, intermediis apice intus vix posticis distincte curvatis. Long. 1.1 mill.

Patria: Brasilia: Sao Paolo (2600 Fufs über dem Meere). Coll. Hans Simon.

Von der vorigen Art durch die kleine, kurze, gedrungene Körperform, die einfacher gebauten Fühler mit zweigliedriger Keule, den breiteren Kopf und die deutlichen Abdominalstrichelchen sehr verschieden.

Mir liegen von dieser Art nur 2 우 vor.

22. Rhexius procerus Rttr. nov. sp.: Elongatus, rufus, pubescens, capite thorace haud angustiore, transverso, rugulose punctato, utrinque oblique impresso, vertice foveolato, prothorace longitudine haud latiore, utrinque dense, dorso parce punctulato, lateribus subtiliter denticulato, collum prothoracis antice brevi, elytris subtiliter punctatis, thorace haud longioribus, stria dorsali valde abbreviata, abdominis segmentis dorsi aequalibus; antennarum articulo primo latitudine triplo longiore. - Long. 3 mill. Taf. V. Fig. 2.

Mas: femoribus anticis intus in medio obtuse lobatis, abdominis segmento quarto dorsali conspicuo longitudinaliter carinato.

Patria: Brasilia: Sao Paolo (3000 Fufs über dem Meere). Coll. Hans Simon in Stuttgart. 
Ausgezeichnet durch die grofse Form und das verhältnifsmälsig kurze erste Fühlerglied; von der nächsten Art durch das Halsschild unterschieden, welches bei dieser so lang als breit ist.

Langgestreckt, gewölbt, fein behaart, rostroth; Kopf sehr quer, aber nicht breiter als das Halsschild, dicht und fein runzelig punktirt, fast matt, nur in der Mitte weniger dicht punktirt und glänzender, jederseits mit zwei vorne sich vereinigenden kurzen Furchen, welche an beiden Enden stärker vertieft sind; Scheitel mit einem Längsgrübchen, das den Hinterrand ganz erreicht. Fühler den Hinterrand des Halsschildes wenig überragend, dünn, das erste Glied nur dreimal so lang als breit, Glied 2 etwas sehmäler, länglich rund, die nächsten dünner, kugelig, Glied 9 und 10 grölser, rundlich, so lang als breit, zusammen so lang als das letzte; dieses grölser, lang eiförmig. Halsschild so lang als breit, herzförmig, die Scheibe spärlich, die Seiten dichter punktirt, mit einer mittleren Längsfurche wie bei allen Arten, vor der Basis mit drei durch eine Querfurche verbundenen Grübchen, die Seiten sehr fein gezähnelt, der Hals vorn kurz, viel kürzer als bei insculptus; Fld. von der Länge des Halsschildes, fein punktirt, mit tiefer Naht und stark abgekürzter Dorsallinie, Humeralfalte etwas erhöht, die Seiten gegen die Spitze leicht erweitert. Die sichtbaren Rückensegmente von gleicher Länge, glänzender und viel spärlicher punktirt. Beine schlank.

Bei dem $\sigma^{*}$ sind die Vorderschenkel auf der Unterseite in der Mitte lappenförmig erweitert und das vierte sichtbare Rückensegm. mit einem Längskiele ausgezeichnet.

Ein Pärchen in der Sammlung des Hrn. Simon in Stuttgart.

Anmerkung. Diese Gattung hat nicht, wie Leconte und Schaufufs sagen, nur eine Klaue an den Füfsen, sondern deutlich 2 ungleiche. Die Schaufufs'sche Tabelle zur Bestimmung der Pselaphiden-Gattungen im Nonquam otiosus p. 243 entspricht durchaus nicht dem Bedürfnisse, welchem der Autor sich unterziehen wollte. Durch die zahlreichen Fehler, die ihr anhaften, ist sie kaum als das zu benutzen, was durch sie bezweckt war. Man vermifst darin eben ein eingehendes selbstständiges Studium. Dafs zur Trennung der Abtheilungen nur die Fühler und Klauen in Betracht gezogen wurden, scheint mir kein glücklicher Gedanke desselben gewesen zu sein, und das Resultat, welches dadurch geschaffen wurde, keineswegs den Anspruch eines natürlichen Systems oder einen bedeutenden Schritt zu einem solchen zu machen.

Ebenso muls ich lebhaft bedauern, dafs Herr Dr. Schaufufs 
bei seinen zahlreichen Neubeschreibungen von Pselaphiden in den seltensten Fällen die Geschleehtsunterschiede, welche bei dieser Familie stets mehr oder minder ausgeprägt vorhanden sind, angiebt.

Wer nur einigermafsen mit diesen interessanten Geschöpfen vertraut zu sein Anspruch machen darf, wird wohl sehr selten in die Lage kommen, das betreffende Geschlecht nicht herauszufinden. Die Geschlechtsdifferenzen gehören zu dem interessantesten Theile ihrer Naturgeschichte, und sind häufig so bedeutend, dafs man dieselben als Merkmale verschiedener Arten $\mathrm{zu}$ halten geneigt sein könnte, wenn man sich darüber nicht klar ist, was zur Trennung der Art und was zur Scheidung des Geschlechts gehört. Aus diesem Grunde möchte ich meinen geehrten Herrn Collegen bitten, bei seinen künftigen Arbeiten über diese Familie uns auch die Geschlechtsdifferenzen kennen $\mathrm{zu}$ lehren, was bisher in den meisten Fällen nicht oder nur sehr unvollständig geschehen ist, weshalb dieselben früher oder später einer Vervollständigung entgegensehen.

23. Rhexius Simonis Rttr. n. sp.: Elongatus, rufus, pubescens, capite thorace vix angustiore, transverso, parce punctulato, utrinque foveolato, inter antennas profunde transversim sulcato, vertice impresso, prothorace longitudine paullulum latiore, sat dense punctulato, lateribus distincte denticulatis, collum prothoracis antice brevi, elytris subtilissime punctulatis, thorace haud longioribus, stria dorsali fortiter abbreviata abdominis segmento primo perspicuo dorsali secundo vix longiore, antennarum articulo primo latitudine triplo longiore. - Long. 3 mill. Taf. V. Fig. 3.

Mas: Capite vertice parvo acute bituberculato, femoribus anticis intus ante apicem lobato-productis, abdominis segmentis dorsalibus simplicibus.

Patria: Brasilia: Sao Paolo (3000 Fufs über dem Meere).

Ich dedicire Herrn H. Simon in Stuttgart diese herrliche Art als kleines Zeichen meiner Anerkennung seiner Mühen, die er zur Entdeckung und Kenntnifs der Pselaphiden und Scydmaeniden aufwendet.

Dem $R h$. procerus täuschend ähnlich, ebenso grofs, von derselben Form, der Kopf ist jedoch anders sculptirt, das Halsschild etwas breiter und dessen Seiten viel stärker gezähnt und die Geschlechtsdifferenzen andere.

Der Kopf zeigt zwischen den Fühlern eine tiefe, gerade, quere Rinne, jederseits neben dem Auge befindet sich ein Grübchen, welches nicht mit dem vorderen Quereindruck in Verbindung steht. 
Der Scheitel ist wie bei der anderen Art eingedrückt. Bei dem $\sigma^{\top}$ trägt der letztere jederseits neben den Scheitelgrübchen ein kleines, spitziges Höckerchen. Die Vorderschenkel des $\sigma^{\top}$ sind wie bei der andern Art auf der Unterseite gelappt, nur ist der Lappen weiter gegen das Knie gerückt; die Rückensegmente sind durchaus einfach.

Ein einzelnes $\sigma^{\widehat{T}}$ von der gleichen Localität der vorigen Art.

Diese beiden Arten sind nun die grölsten bis jetzt beschriebenen der Gattung.

24. Rhexius rugulosus Rtt. n. sp.: Parvulus, rufus, tenuiter pubescens, antennarum articulo primo latitudine triplo longiore, secundo quadratim subrotundato, articulis $3-8$ angustis, parvis, valde transversis, clava triarticulata, articulis duobus penultimis maxime transversis, ultimo magno, leviter ovato; capite thoraceque confertissime rugoso-punctatis, opacis, hoc haud transverso, capite vix angustiore, longitudinaliter sulcato, sulco basali transverso foveolaque media tenuibus, lateribus haud denticulato, collo antice brevi, elytris abdomineque nitidis, illis parce subtilissime punctulatis, thorace latioribus et parum longioribus, stria dorsali valde abbreviata. -. Long. 1.1 mill.

Patria: Columbia: Barrunquilla. Coll. Reitter.

Diese sehr kleine Art, welche sich von den bekannten durch den matten Kopf und ein gleiches Halsschild, was durch die dichte, runzlige Punktirung hervorgerufen wird, auszeichnet, hat ebenfalls nur ein verhältnifsmäfsig kurzes erstes Fühlerglied. Ich besitze ein einzelnes 오.

\section{Trimiopsis nov. gen.}

Corpus elongatum, convexum, ut in gen. Trimio. Antennis undecimarticulatis, brevibus, clavatis, basi distantibus, palpis quadriarticulatis, articulo ultimo leviter securiformi, coxis posticis approximatis, abdomine late marginato, segmento ventrali secundo tertioque parum majori, segmentis primis dorsalibus aequalibus; tarsorum unguiculo singulo.

Mit Trimium sehr nahe verwandt und durch die gleichlangen Dorsalsegmente und den verlängenten zweiten und dritten Bauchring, endlich schwach beilförmiges Endglied der Palpen verschieden. 
25. Trimiopsis claviceps Rtt. nov. sp.: Elongatus, leviter convexus, subpubescens, testaceus, elgtris palpis pedibusque pallidis, capite subquadrato, magno, thorace latiore, temporibus magnis, parallelis, fronte antice fortiter bifoveolato, inter foveam tuberculo instructo, margine frontali antice inter antennas leviter rotundato, antennis brevibus, antennarum articulis basalibus duobus parum incrassatis, articulo 2 subgloboso, ceteris angusioribus, 3 obconico, subquadrato, $4-8$ transversis, ultimis tribus clavam magnam ovatam formantibus, articulo 9 maxime transvevso, 10 transverse triangulare, ultimo maximo; prothorace subcordato, latitudine fere longiore, ante basin foveolis tribus cum sulco transverso conjunctis; elytris thorace latioribus et longioribus, subparallelis, stria suturali integra, dorsali parum abbreviata, his basi profundiore, abdomine parallelo, segmentis tribus perspicuis primis dorsalibus aequalibus, late marginatis. - Long. 1.3-1.4 mill. Taf. V. Fig. 9.

Patria: Columbia: La Luzera. Coll. Reitter 우.

Gas ola nov. gen.

Corpus elongatum, subdepressum. Antennis undecimarticulatis, gracilibus, haud clavatis, basi approximatis, palpis quadriarticulatis, articulo ultimo fusiformi, capite subtus bicarinatis, carinis postice convergentibus, mentum magnum, antrorsum productum, os subobtegens, temporibus magnis, postice rotundatis, fronte bisulcata, sulcis approximatis, postice foveolatis, oculis granulatis, magnis, vix rotundatis, thorace lateribus mucronato, sulca transversa subarcuata antebasali et utrinque foveola impressis; elytris stria dorsali distincta, discoidali valde abbreviata, sublaterali prope humeros nulla, coxis posticis approximatis, abdomine late marginato, segmentis dorsalibus et ventralibus quatuor primis conspicuis aequalibus, tarsorum unguiculis binis aequalibus.

Mit Sagola Sharp und Faronus verwandt; der Kopf hat abgerundete Schläfen, auf der Unterseite zwei gegen das Halsschild zusammenlaufende Kiele, der Mund ist zum grölsten Theile von dem verhältnifsmäfsig grofsen Mentưm bedeckt, die Augen sind ziemlich grofs, grob granulirt, nach unten zu zugespitzt, die Fld. haben keinen Sublateralstreifen (wie bei Trichonyx), weshalb der umgebogene Theil nicht abgegrenzt wird, das Halsschild ist an den Seiten mit einem scharfen Zähnchen wie bei Trogaster bewehrt. Bei einer anderen noch unbeschriebenen, dieser sehr nahe verwandten und ähnlichen Gattung aus Westindien sind die Fühler deutlicher keulenförmig, die Augen rudimentär, das Halsschild 
hat eine Mittelfurche und die Flgd. wie bei Trichonyx mit einer deutlichen Sublateralfurche.

26. Gasola Simoni Rttr. n. sp.: Testacea, subpubescens, capite magno, thorace angustiore, antrorsum angustato, laevi, sulcis frontalibus approximatis, subparallelis, postice abbreviatis, foveolatisque, prothorace transverso, subcordato, prope basin constricto, sulca transversa utrinque foveolata profunde impressis, lateribus pone medium dentato, elytris thorace vix latioribus sed plus quam sesqui longioribus, subparallelis, subtilissime vix perspicue punctulatis, stria suturali punctiformi, callo humerali parum distincto, abdomine elytris haud angustiore, sat brevi, late marginato, vix perspicue subtilissime punctulato. - Long. 1.4--1.5 mill. Taf. V. Fig. 1.

Patria: Brasilia: Sao Paolo (4000 Fuls über dem Meere). Coll. Hans Simon.

Die Fühler ron mälsiger Länge, den Hinterrand des Halsschildes etwas überragend, die beiden Wurzelglieder von der Stärke des 4 ten und 5ten, Glied 3 und 4 klein quadratisch, 5-10 quer, allmählig etwas breiter werdend, 11 lang eiförmig, zugespitzt.

Mir liegt ein einzelnes $\widehat{\jmath}$ dieser Art vor; die Schenkel desselben sind als solches ziemlich verdickt, der Bauch besteht aus sieben fast ganz gleich langen Segmenten (beim + sicher 6) und das Analsegment besitzt eine grofse, flache Grube.

Ich dedicire diese schöne Art ihrem Besitzer, Herrn Hans Sinon in Stuttgart.

\section{Scydmaenidae.}

1. Euconnus fimbriatulus Rttr. n. sp.: Parvulus, aureo hirtus, rufo-piceus, capite elytrorum dorso fusco castaneis, antennis palpis pedibusque testaceis, antennarum art. duobus primis leviter incassatis oblongis, subcylindricis, 3-8 quadratis, clava triarticulata, art. duobus penultimis sensim latioribus, subtransversis, ultimo ovato, a obus penultimis summo longitudine fere aequali; capite thorace agustiore, subrotundato, introrsum linea transversa subimpressa; pothorace subelliptico, oblongo, antrorsum parum magis attenuato, hevi, basi vix foveolato, longe aureo hirto, angulis posticis dense areo-pubescens; elytris obovatis, basi thorace latioribus, dein senim ampliatis, laevibus, impressione basali obsoleta lataque, callo umerali minus producto. - Long. 1 mill.

Patria: Brasilia: Sao Paolo (2600 F. ü. d. M.). Coll. Simon.

Gehört in die Verwandtschaft unseres Euc. nanus Schaum. 
152 E. Reitter: über neue Pselaphiden u. Scydmaeniden etc.

2. Euconnus conicus Rttr. n. sp.: Piceo-rufus, palpis pedibusque testaceis, pilosus, antennis mediocribus, dimidio corporis longitudine, apicem versus sensim incrassatis (articulis 5 ultimis paullulum majoribus), articulo 2 obconico, oblongo, ceteris minoribus, 3-6 subquadratis, $7-10$ fere quadratis, ultimo ovato, oblongo; capite late obovato, thorace vix angustiore, collo longo, fronte laevi; prothorace latitudine parum longiore, conico, basi bifoveolato; elytris ovatis, ampliatis, parcissime subtilissimeque punctatis, basi bifoveolatis, foveola externa majore, extus divergenta, interiore punctiformi, parvula; callo humerali obtuso. -- Long. 1.4 mill.

Patria: Brasilia: Sao Paolo (3000 Fuls über dem Meere). Coll. Hans Simon.

Gehört in die Untergattung Napochus Thoms.

Erklärung der Figuren auf Tafel V.

Fig. 1. Gasola Simoni Rttr.

- 2. Rhexius procerus Rttr.

- $3 . \quad$ - $\quad$ Simonis Rttr., Halsschild.

- 4. Apharus Mülleri Rttr.

- 5. Batrybraxis fortis Rttr.

- 6. Batrisus clypeatus Rttr., Kopf.

- 7. - Phanthasma Rttr., Kopf.

- 8. - brevispinus Rttr., Kopf.

- 9. Trimiopsis claviceps Rttr., Kopf.

- 10. Bryaxis biclavata Rttr., Kopf.

- 11. Xybaris spiniceps, Rttr., Kopf. 


\section{$2 \mathrm{BHL}$ Biodiversity Heritage Library}

Reitter, Edmund. 1882. "Neue Pselaphiden und Scydmaeniden aus Brasilien." Deutsche entomologische Zeitschrift 1882(2), 129-152. https://doi.org/10.1002/mmnd.48018820221.

View This Item Online: https://www.biodiversitylibrary.org/item/103947

DOI: https://doi.org/10.1002/mmnd.48018820221

Permalink: https://www.biodiversitylibrary.org/partpdf/235214

\section{Holding Institution}

Harvard University, Museum of Comparative Zoology, Ernst Mayr Library

\section{Sponsored by}

Harvard University, Museum of Comparative Zoology, Ernst Mayr Library

\section{Copyright \& Reuse}

Copyright Status: Public domain. The BHL considers that this work is no longer under copyright protection.

This document was created from content at the Biodiversity Heritage Library, the world's largest open access digital library for biodiversity literature and archives. Visit BHL at https://www.biodiversitylibrary.org. 